\title{
Putting It Together: A Model for Integrating Injury Control System Elements
}

\author{
Ricardo Martinez, MD
}

Administrator, National Highway Traffic Safety Administration, U.S. Department of Transportation

Correspondence: National Highway Traffic Safety Administration, 4007 th St., S.W., Room 5220, Washington DC 20590

This article was developed by the National Highway Traffic Safety Administration (NHTSA) Health-Care Taskforce, chaired and directed by Dr. Ricardo Martinez, to articulate a vision for injury control within NHTSA.

This document is in the public domain and may be reproduced without permission from the editor or publisher

Key Words: costs; data analysis; data collection; death; disability; injury; injury control; leadership; monitoring; partnership; prevention; rehabilitation; research; resources; systems

\section{Introduction}

Injury is the leading cause of death for persons from age 1-44 years, and is the most common cause of hospitalizations for persons less than the age of 40 years. The financial costs of injuries are staggering: injuries cost billions of dollars in health-care and social support resources (Figure 1). For example in 1990, the lifetime costs of all injuries in the United States were estimated at [US] $\$ 215$ billion annually. These estimates do not include the emotional burden resulting from the loss of a child, or the loss of a loved one, or the toll of severe disability on the injured person or his/her family.

Injury control has come a long way in the 10 years since the publication of Injury in America. Many of the far-sighted recommendations of that publication have been implemented. However, injury has not received the same level of public attention and resources as have other health issues, and despite recent progress, injury remains a major public-health problem.
Resources must be used more effectively to meet the challenge posed by injuries.

\section{Vision}

Building on past efforts, a new vision for the future of injury control emerges. This vision inspires action toward an integrated injury control system, where linkages and partnerships exist among the system components, as well as with business, government, health care, and community groups working together to reduce the toll of injuries. When partners work in concert, the scope of injury control efforts can be broadened to address all injuries systematically, and thus, reduce the overall costs of injury to society.

\section{Partners}

The injury problem is too large and too complex, and resources are too limited for any one group to solve. Potential partners include all of those having a stake in reducing injuries (Table 1 ). This includes those who are traditional stake-

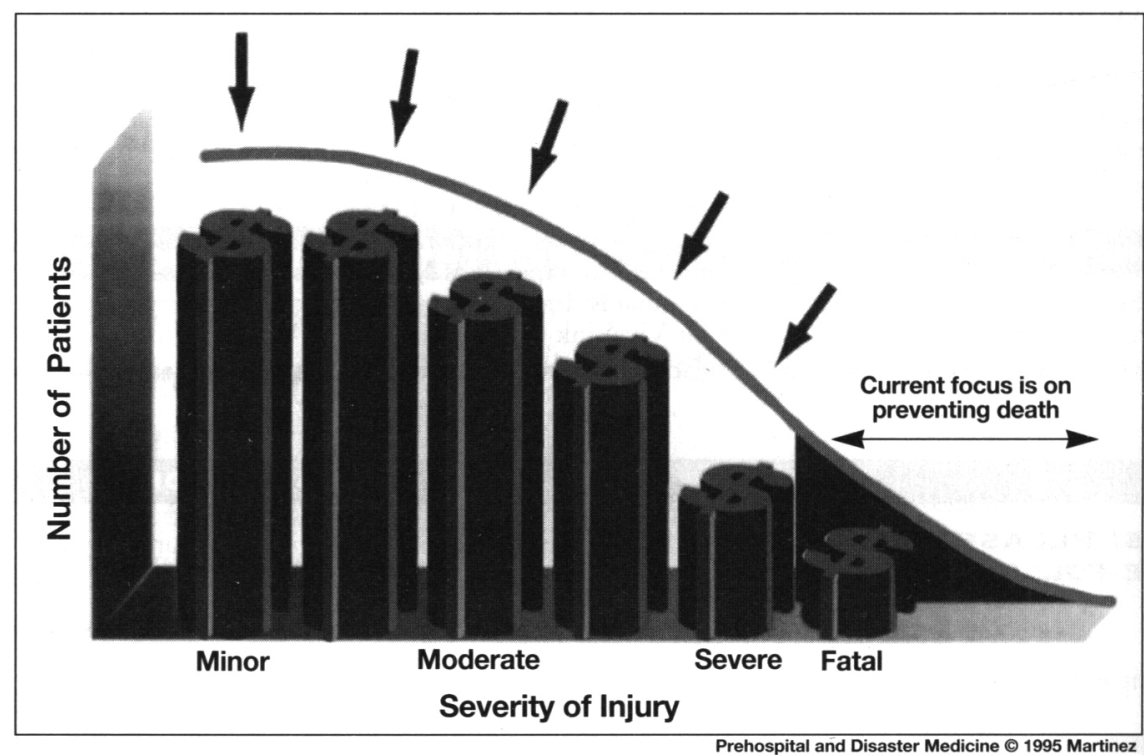

Figure 1-Costs of injury to society. Most of the resources currently are directed to prevention of death while most of the economic and social costs are associated with nonfatal injuries. 


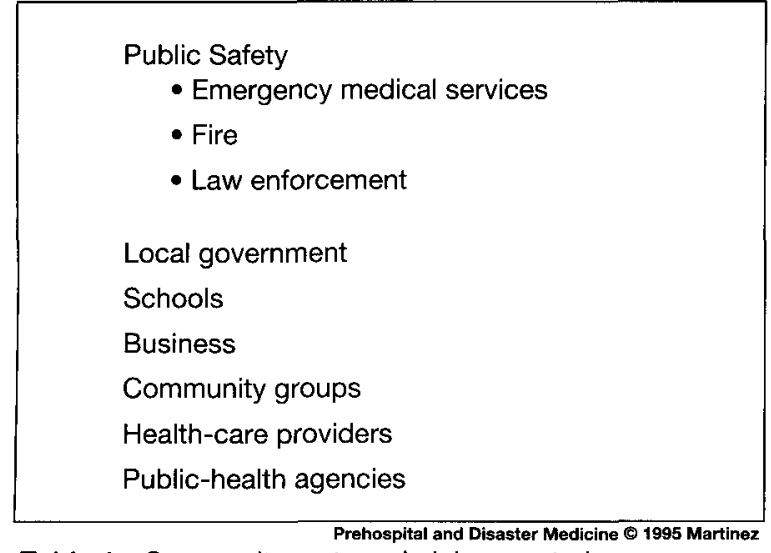

Table 1-Community partners in injury control

holders-e.g., health-care practitioners, emergency medical technicians, public-health professionals, safety advocates-as well as those who readily may not identify with the traditional injury control community-law enforcement, business, local government, schools, etc. This new vision for injury control enlightens individuals and groups to the role each plays in reducing injury and encourages new coalitions and partnerships.

\section{System Components}

The injury control system consists of three integrated components: 1) prevention; 2) acute care; and 3) rehabilitation (Figure 2). Each of the three components of the injury control system currently operates as an extensive, highly evolved, independent system. To accelerate progress in reducing injuries, the three components must operate as a synergistic system, whereby, for example, data from one component are used by another component to identify emerging problems, allocate resources, and develop effective interventions.

Prevention approaches seek to avert injury. This is accomplished by: 1) identifying the causes of injury and those at risk for different types of injury; 2) developing and implementing effective interventions; and 3) evaluating the effectiveness of the interventions on the populations at risk. Prevention programs reduce injuries by: 1) changing behavior (wearing a safety belt, not drinking and driving, lowering household water temperatures); 2) making a safer product (air bags, anti-lock brakes, using materials that absorb energy); or 3) creating a safer environment (fencing around pools, smoke detectors, improved roadway lighting and markings). Over the long term, prevention approaches are more cost-effective than is treatment.

Acute care systems provide accessible and appropriate care to all patients regardless of the nature and severity of injury. As some injuries will occur despite the best prevention efforts, an integrated injury control system must include approaches for dealing with an injury once it occurs. The outcome of an injury depends not only on its severity, but also on the speed and appropriateness of medical treatment provided. The goal of the acute care system is to ensure that every patient receives optimal

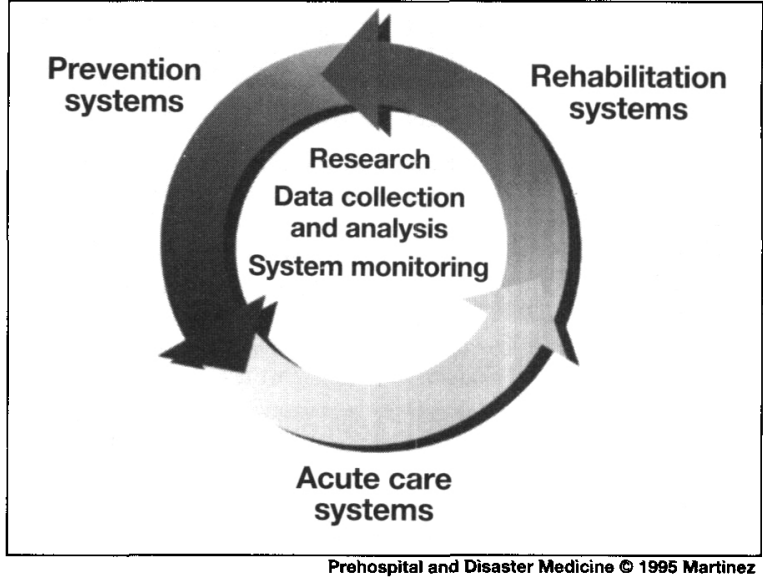

Figure 2-Components of an injury control system

care from the initial recognition of injury through return to the community.

Rehabilitation systems help the injured patient to return to the home and work environments. Rehabilitation is the process by which biological, psychological, and social functions are restored or developed to permit the injured person to be integrated back into society and lead a productive and independent life. Early and aggressive rehabilitation can reduce long-term costs to employers and society by returning workers to the work force, decreasing disability and workers' compensation costs, and increasing overall productivity.

In addition, data collection and analyses, research, and system monitoring serve as the critical links among the three system components. Data document what occurs. Research uses data to identify injury mechanisms and develop strategies_-both preventative and treatmentbased-for reducing injuries. System monitoring provides an index of how the injury-control systems perform.

\section{The System in Action}

Partnerships and leadership are the foundation for making the injury control system work. Linkage must occur among the system components, as well as among potential partners. Given the cost of injury to society and the consequences of injury on human lives, more widespread and innovative efforts must emerge to reduce injury. Business, government, law enforcement, health-care providers, and civic and advocacy groups at the national, state, and local levels must join forces and work together across the injury control system (Figure 3). Leadership is required to coalesce these divergent groups and interests into a comprehensive approach to injury.

By working in partnership, injury control stakeholders can avoid fragmentation and duplication of efforts and reinforce each other's programs and messages. By marshaling resources and data through partnerships, communities can create innovative solutions to their injury problems. More can be accomplished by working together than by working alone.

Injury control programs (e.g., drowning, falls, motor vehicle, violence, poisoning, occupational) must explore 


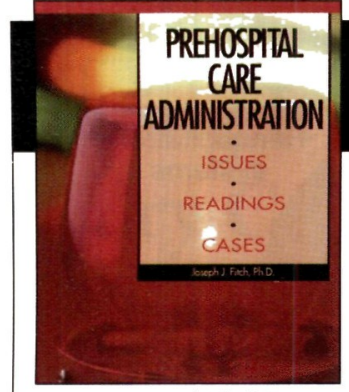

$\$ 42.95$
Prehospital Care Administration: Issues, Readings, Cases

Edited by Joseph J. Fitch, PhD

This book is a compilation of original articles, written by a diverse group of EMS leaders and previously published in JEMS and other key professional journals and trade magazines. It serves as a ready reference for every EMS administrator Topics range from handling human resources issues to reimbursement and EMS system design. More than 100 articles represent

both landmark cases shaping the profession as well as original article which offer new insights for the future.

Call: The Jems Bookstore at $800 / 266$-JEMS.

\section{Times Have Changedl}

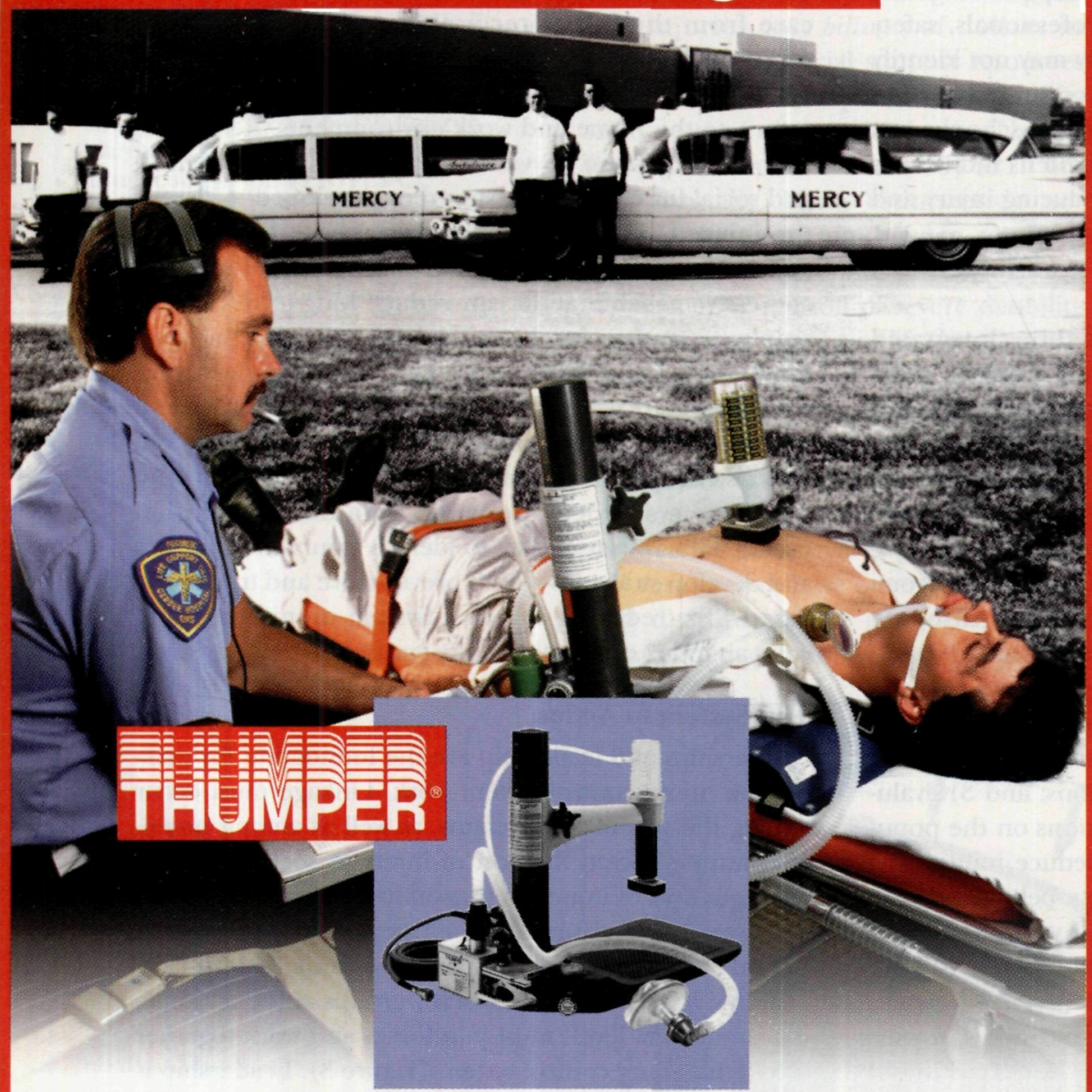

The Thumper ${ }^{\circledR}$ System meets the needs of today's EMS providers. Don't make your patients settle for less. Thumper CPR, The Gold Standard in CPR Performance. Call for information and references 1-800-530-9939.

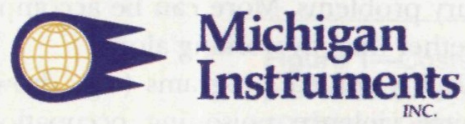

\section{PROYI LIt} We Challenge You!

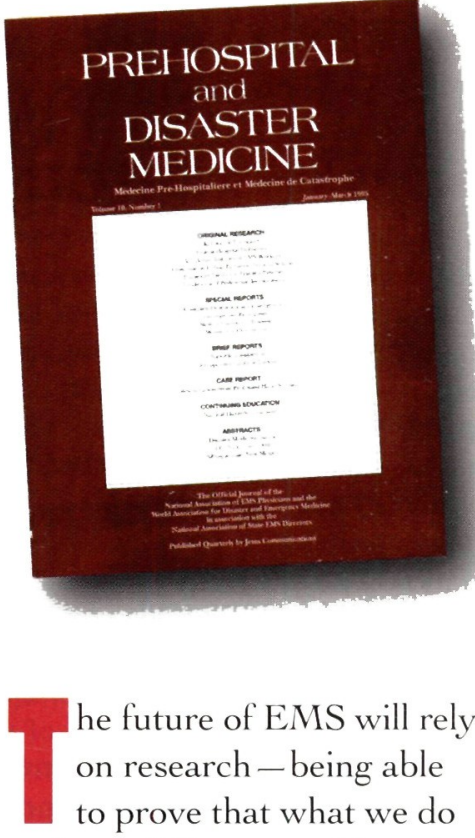
makes a difference. Although the statistics aren't always easy, they are at the heart of the matter. Take the challenge! Subscribe to PREHOSPITAL AND DISASTER MEDICINE. You'll get the best scientific research available to the EMS community and be a part of the future!

\section{Try it-risk free!}

Return the enclosed card for a one-year subscription

(4 issues) for only $\$ 39$.

This is a risk-free subscription. You can cancel at any time for a full refund.

If card is missing, call (800) 266-JEMS. 
$\checkmark$ Yes! Please enter my subscription to PDM for:

1 year (4 issues): $\square \$ 89$ Institutional $\square \$ 55$ Individual $\square \$ 39$ Resident/ln Training 2 years (8 issues): $\square \$ 159$ Institutional $\square \$ 95$ Individual

$\square \$ 69$ Resident/In Training

$\square \$ 39$ AMT, Paramedic, RN $\square \$ 69$ AMT, Paramedic, RN

NOTZ: "Institutional defines multiple reader subscriptions, including libraries, haspitals, government agencies, and all private organizations, Individual subscriptions must be paid by individuals.

Name/Institution

Address

City State Zip

$\square$ Payment enclosed $\square$ Bill me $\square$ Charge my: $\square$ Visa $\square$ MasterCard $\square$ Discover $\square$ AMEX

Exp. Date

Canada -plrase add $\$ 6$ per year for paslage, phus Card \#

laxes. All other fowign-please add \$8 prr year.

Air mail -add 520 per year. Allow 3-12 aweks for Signature

shipment of first issue.

Make checks payable to PDM, P.O. Box 2789, Carlsbad, CA 92018

654ZA-1

$\begin{array}{lll}\text { Occupation: } & \text { Employment Location: } & \text { Primary SPECIALTY (if Physician): } \\ \square \text { Physician } & \square \text { Hospital } & \square \text { Emergency Medicine } \\ \square \text { Nurse } & \square \text { Fire Dept./Rescue Squad } & \square \text { Critical Care } \\ \square \text { EMT Paramedic } & \square \text { Ambulance Service } & \square \text { Traumatology } \\ \square \text { Administrative/Supv/Purch. Agent } & \square \text { Regional/State/Federal Agency } & \square \text { Prehospital Medical Director } \\ \square \text { Disaster/Civil Defense Planner } & \square \text { Industry } & \square \text { Cardiology } \\ \square \text { Other } & \square \text { Other } & \text { Other }\end{array}$

Prehospital and Disaster Medicine offer Exphes 731/95

$\checkmark$ Yes! Please enter my subscription to PDM for:

1 year (4 issues): $\square \$ 89$ Institutional $\square \$ 55$ Individual $\square \$ 99$ Resident/In Training $\square \$ 39$ AMT, Paramedic, RN 2 years (8 issues): $\square \$ 159$ Institutional $\square \$ 95$ Individual $\square \$ 69$ Resident/In Training $\square \$ 69$ AMT, Paramedic, RN

NOTE: "Institutional defines multiple reader subscriptions, including libraries, haspitals, government agencies, and all privale organizations, Individual subsrriptions must be paid by individuals.

Name/Institution

Address

City

State Zip

$\square$ Payment enclosed $\square$ Bill me $\square$ Charge mỵ: $\square$ Visa $\square$ MasterCard $\square$ Discover $\square$ AMEX

Canada-ploase add \$6 per year for postage, plus Card \#

taxes. All other foncign-please add $\$ 8$ per year.

.4ir mail -add \$20 per year. Allow 3-12 weeks for

shipment of firs/ issue.

Signature

Make checks payable to PDM, P.O. Box 2789, Carlsbad, CA 92018

$654 Z A-1$

\begin{tabular}{|c|c|c|}
\hline $\begin{array}{l}\text { Occupation: } \\
\square \text { Physician } \\
\square \text { Nurse } \\
\square \text { EMT Paramedie } \\
\square \text { Administrative/Supv./Purch. Agent } \\
\square \text { Disaster/Civil Defense Planner } \\
\square \text { Other }\end{array}$ & $\begin{array}{l}\text { Employment Location: } \\
\square \text { Hospital } \\
\square \text { Fire Dept./Rescue Squad } \\
\square \text { Ambulance Service } \\
\square \text { Regional/State/Federal Agency } \\
\square \text { Industry } \\
\square \text { Other }\end{array}$ & $\begin{array}{l}\text { Primary SPECIALTY (if Physician): } \\
\square \text { Emergency Medicine } \\
\square \text { Critical Care } \\
\square \text { Traumatology } \\
\square \text { Prehospital Medical Director } \\
\square \text { Cardiology } \\
\square \text { Other }\end{array}$ \\
\hline
\end{tabular}

National Association of EMS Physicians

$\square$ YES!! Please send me a membership application and more information about NAEMSP.

\section{Name}

Title

Organization

\section{Address}

\section{City}

State

Zip

Membership Includes:

- Subscription to Prehospital and Disaster Medicine and NAEMSP News National EMS Database - Discounted Annual and Mid-Year Meeting Registration Fees The advantage of networking with the most designated, medical legally responsible municipal and state EMS systems \& EMS programs. 
A peer-reviewed

journal dedicated entirely

to the science of EMS

BUSINESS REPLY MAIL

POSTAGE WILL BE PAID BY ADDRESSEE
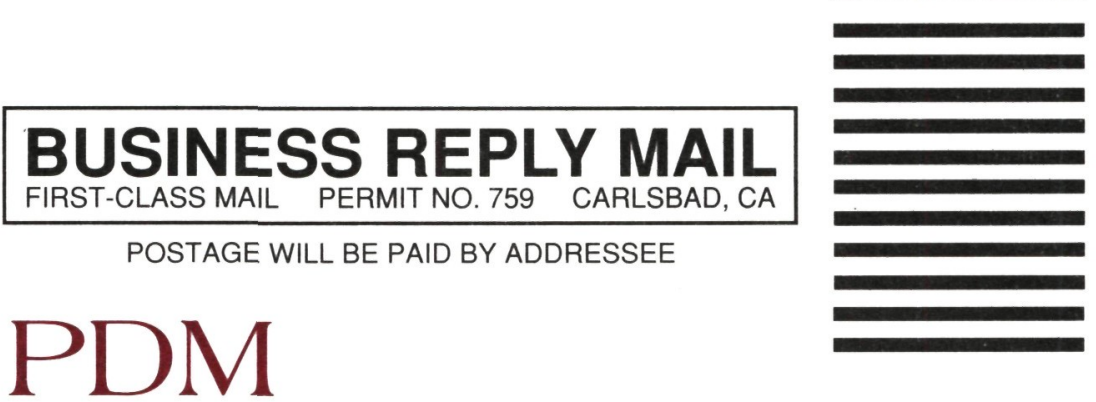

PO BOX 2789

CARLSBAD CA 92018-9898

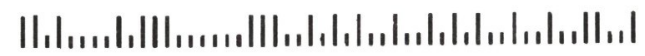

A peer-reviewed

journal dedicated entirely

to the science of EMS

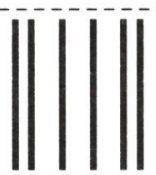

\section{BUSINESS REPLY MAIL}

FIRST-CLASS MAIL PERMIT NO.759 CARLSBAD, CA

POSTAGE WILL BE PAID BY ADDRESSEE

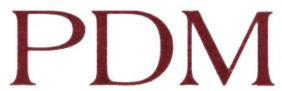

PO BOX 2789

CARLSBAD CA 92018-9898

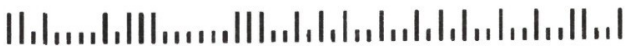

National Association of EMS Physicians 230 McKee Place, Suite 500

Pittsburgh, PA 15213 


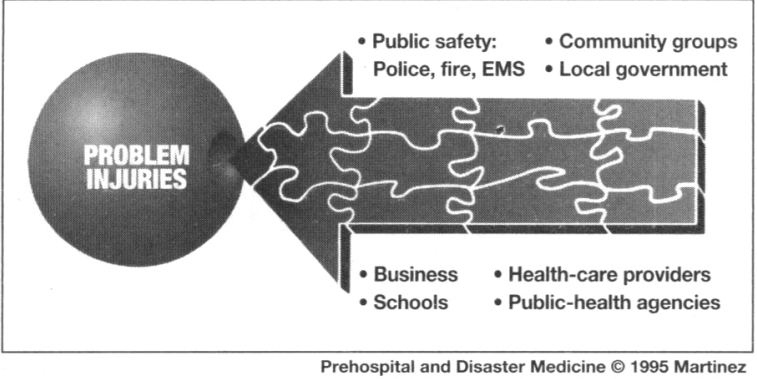

Figure 3-Attacking the injury problem through community partnerships

existing partnerships and decide whether additional partnerships are needed to make the system work. A strategy for establishing new relationships and bringing new partners into the system must be developed. Recognition of the high cost of injury and its contribution to health-care costs can serve as a catalyst for engaging new partners.

\section{System Implementation}

Often, it seems difficult to improve health and safety because the problems seem so complex, and intervention strategies have too many implications. So, people sometimes wait for others to take the first step or for an event to propel them into action. Implementing a comprehensive injury control model clearly requires leadership and an ability to bring together many diverse interests. Leadership can come from different sources-government, the health-care community, civic groups, and employers. Once commitment is made to focus on injury, the stakeholders must decide what problems need to be addressed, what resources they bring to possible solutions, what role they will play in controlling injuries, and how they will work together to reduce injuries.

Leadership in reducing death and disability from traffic crashes traditionally has come from federal government, state highway safety offices, law enforcement, advocacy groups, and emergency medical services. These groups long have recognized the toll of traffic crashes in terms of pain, suffering, and costs. However, these traditional traffic safety partnerships must be expanded to include new and emerging partners and to better integrate health and medical providers, business, and local government into comprehensive traffic safety-injury control efforts.

Govermment can take a leadership role in injury control by galvanizing partners, such as law enforcement agencies, courts, civic organizations, employers, healthcare providers, and the media to support injury control activities, establish policies, and initiate environmental changes to reduce injury in the community. Govern-
1. Build an injury control coalition with relevant stakeholders

2. Use community data to identify injury problems and causes

3. Develop and test solutions and interventions based on consensus

4. Implement interventions

5. Evaluate intervention process and outcomes using coalition-generated targets

Prehospital and Disaster Medicine (- 1995 Martine

Table 2-Steps for implementing injury control and prevention programs

ment also can provide the leadership needed to identify problems, determine priorities, and design prevention programs that will reduce the incidence of injuries.

Health-care providers see first-hand, the effects of injuries - especially in terms of human pain and suffering. Moreover, the focus on reducing health-care costs by changing financing incentives is shifting the focus of care from treatment to prevention. Involving health-care providers in preventing and mitigating injuries can help communities redirect scarce resources from the treatment and care of injured persons into the community health promotion and wellness programs.

Business has an increasing role in injury control. Injuries-both on- and off-the-job-not only cost employers in terms of outlays for health insurance and workers' compensation, but also result in lost productivity and work days, and increased insurance premiums. Longterm disability is extremely costly, and business bears not only the costs of rehabilitation, but those costs associated with backfilling positions and training replacement employees. Business can examine internal data to track the incidence and costs of injuries, establish policies for on-the-job safety, and form partnerships to reduce injuries, lost work days, and lost productivity.

Efforts to implement an integrated injury control system will employ strategies similar to those models used in implementing other programs in communities and organizations (Table 2). There are many program implementation models, but most share similar elements. What is important to keep in mind is that new partnerships provide fertile ground for exploring innovative ways to approach old, as well as emerging problems.

Stakeholders can use this new conceptual framework to align partners and move forward with a consolidated approach to injury control. The injury control community now must refine and hone these concepts and develop additional strategies for implementing these ideas. 


\section{If you didn't buy a Wheeled Coach, you only bought half of an ambulance...}

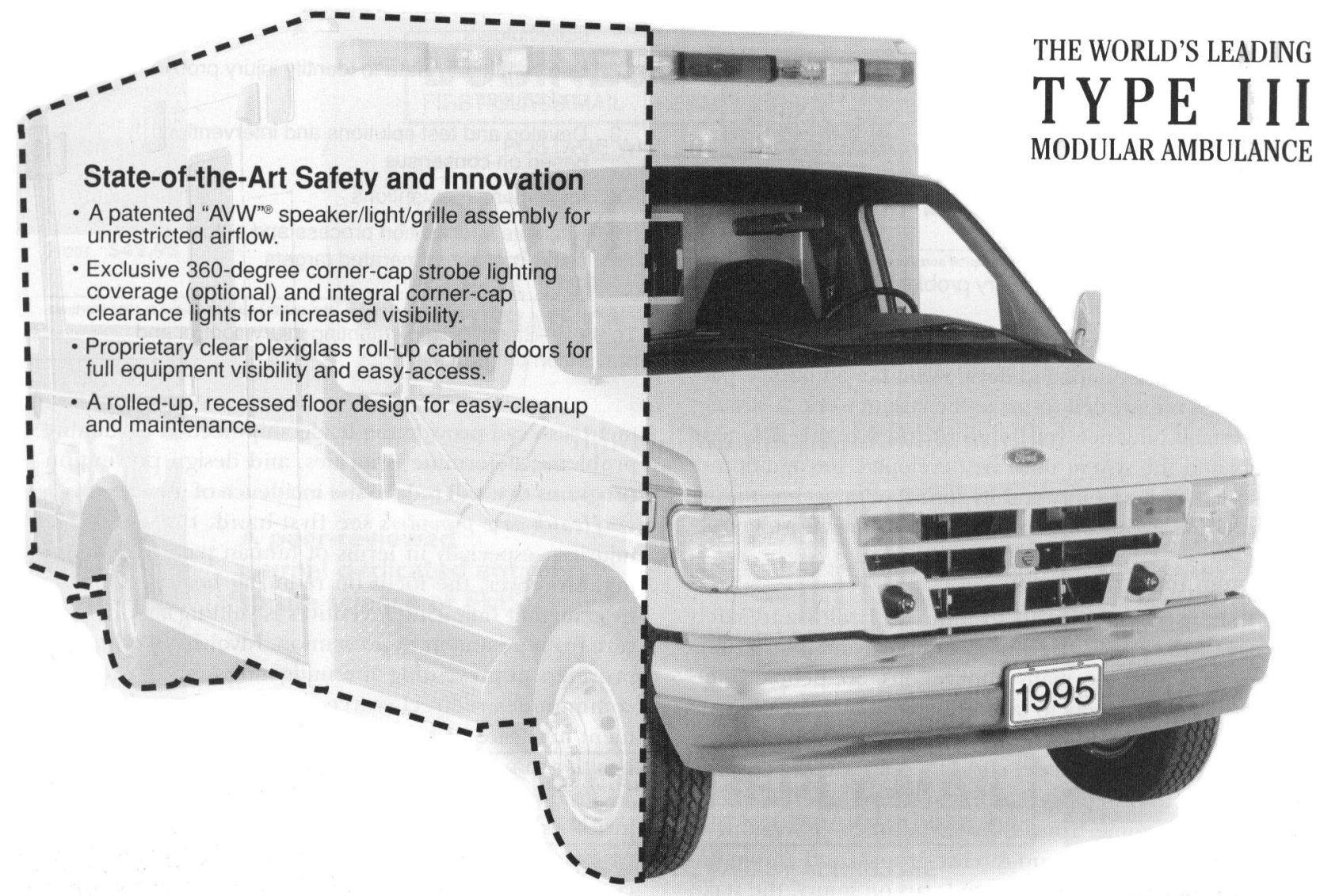

\section{Because "down-the-road," the other half is service!}

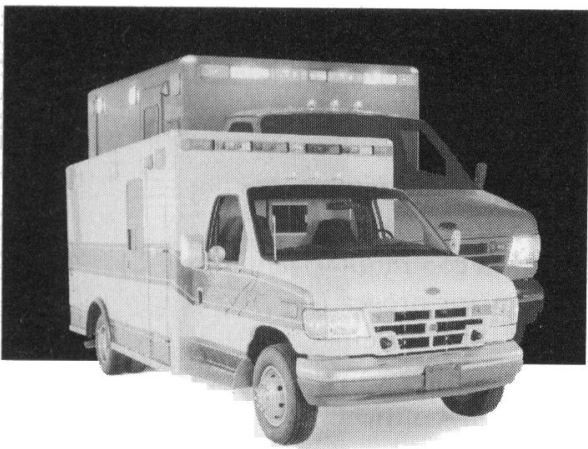

Wheeled Goach Delivers A Complete Package!

When you buy a Wheeled Coach, you buy more than just an ambulance. You buy our exclusive guarantee that "down-the-road" you will always have the service you need 24-hours-a-day!

Wheeled Coach's unique, 24-Hour (tollfree) Emergency Service Hotline guarantees you an immediate source for problem-solving assistance and mechanical expertise - from anywhere in the USA or Canada. So, no matter what time it is, or where you are located, you'll be contacted "within the hour" - that's our special promise! And, our staff has built a long-standing reputation for solving most of our customers' problems on-the-spot!

Did you know that Wheeled Coach also houses the biggest Parts, EMS Supply and Customer Support Departments in the industry? And that, we've developed to meet your needs, the largest Support Distribution Network of factory-trained service technicians in the world? And, every complete vehicle we manufacture is backed by a comprehensive Product Liability Insurance - the best on the market! Plus, every 60 days we offer you a 2-Day Service Seminar conducted by a factory-team of technical trainers - with over 25 years of combined ambulance experience and expertise.

It all adds up! When you buy a Wheeled Coach, you buy more than just an ambulance, because we know that "down-the-road" you'll need more than just empty promises. Maybe that's why we're the leading manufacturer of ambulances in the world.

So, bring in the other half of your ambulance and let's sit down and talk about the real meaning of our service and support!

Or, call us today, at 1-800-342-0720, for additional information.

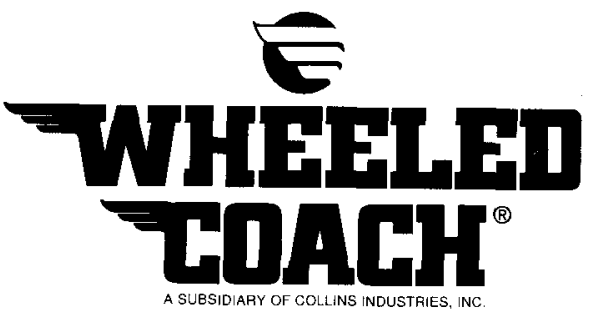

The World's Leading Manufacturer of Ambulances 


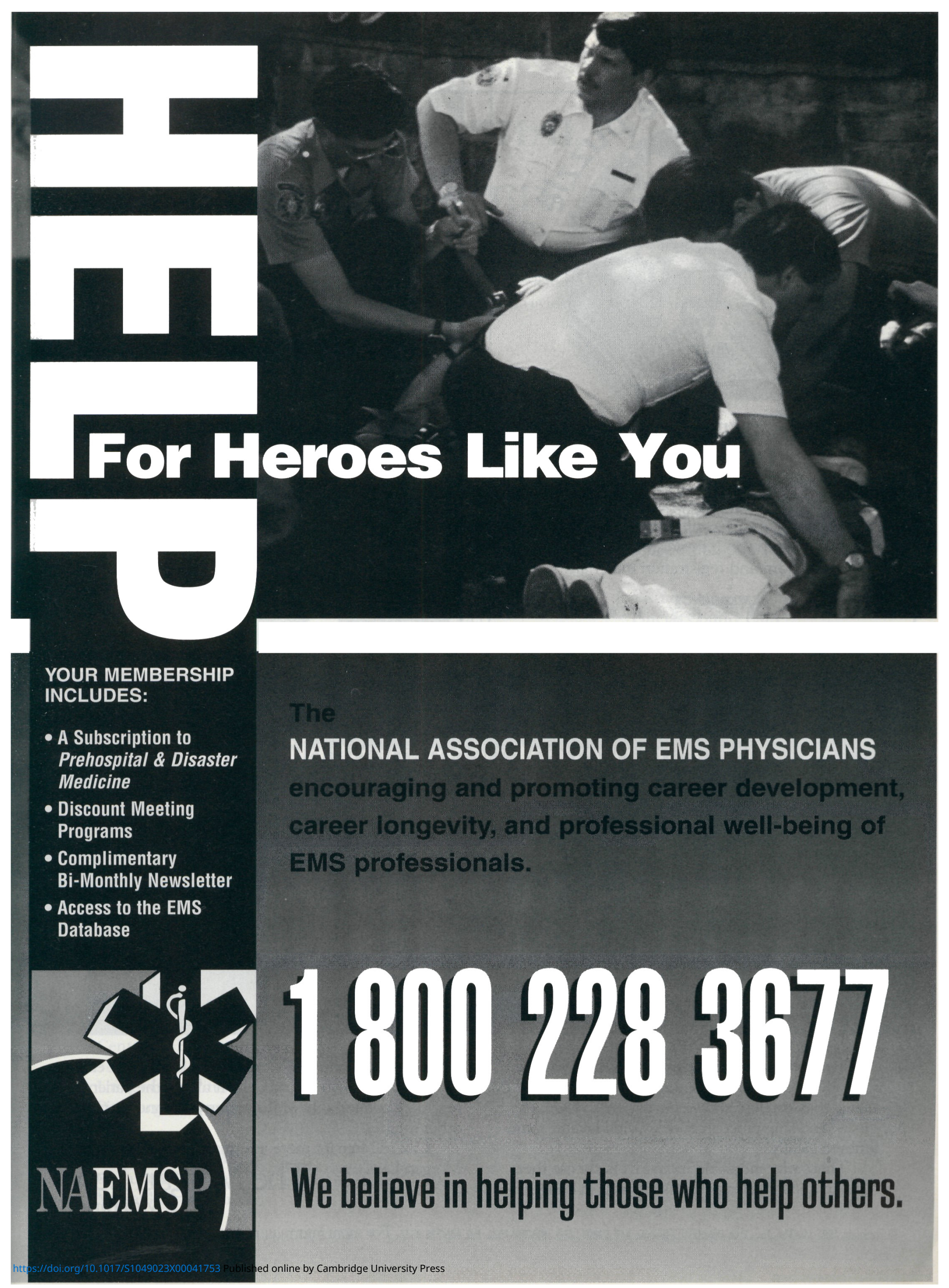



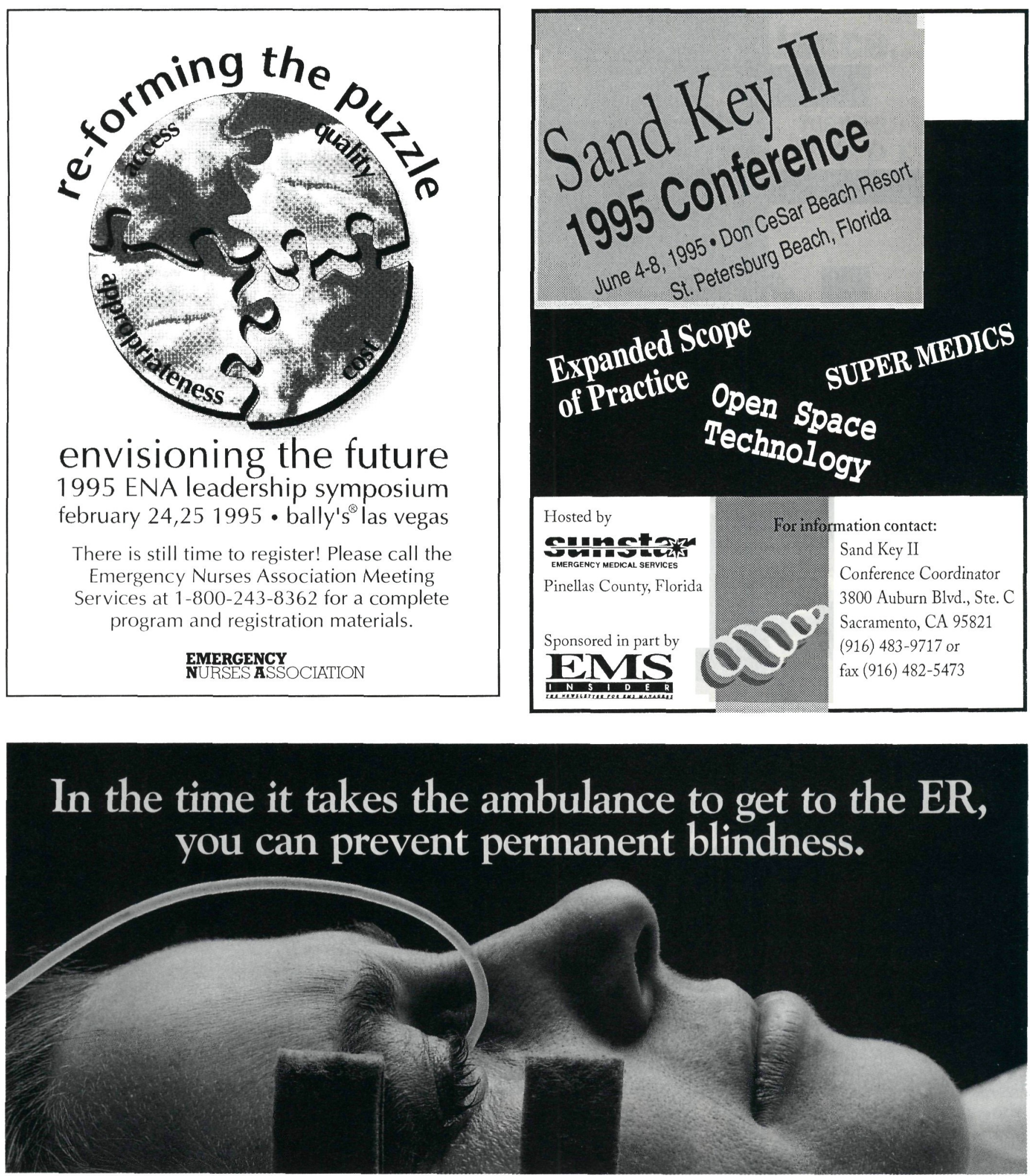

Eye injuries are nothing to take chances with.

They may be no more serious than dust in the eye; they can also threaten a patient's vision. Patchand-ship procedures delay vital lavage, sometimes tragically.

That's why more and more EMTs choose the Morgan Lens when a patient's vision is in danger.
Applied in seconds, the Morgan Lens is the most effective eye-lavage system available. It allows the patient to rest more comfortably while freeing personnel to treat other injuries.

Call toll-free for more information, or to order the Morgan Lens.
The Morgan Lens 